\title{
TRANSMISSION CONGESTION MANAGEMENT USING FUZZY LINEAR PROGRAMMING TECHNIQUE IN COMPETITIVE MARKET
}

\author{
Adel A. Abou El-Ela ${ }^{*}$, Ahmed Shobir ${ }^{* *}$, Ahmed Shobir ${ }^{* *}$ and S.Dawoud ${ }^{* *}$ \\ Electrical Power Department, Faculty of Engineering, \\ *Minoufiya University, Minoufiya, Egypt \\ **Tanta University, Tanta, Egypt
}

\begin{abstract}
This paper presents a proposed optimization technique (POT) for transmission congestion management problem in competitive power systems at normal and emergency conditions. The fuzzy linear programming (FLP) is used as intelligent optimization technique for solving transmission congestion management problem. Two shapes modeling of fuzzy memberships are used and compared with the linear programming technique, as a conventional optimization technique. The POT has two objectives which are: Minimizing the cost of generation, maximizing the profit. However the profit is the difference between the market revenue and market payment. A multi-objective function of fuzzy technique is used to find the maximum profit for different shapes of fuzzy membership models. Four standard test systems are used to extensive study of the POT. One of these test systems is a real system of the Egyptian United Network. Simulation results show that the POT is more accurate and efficient, especially with large scale power system.

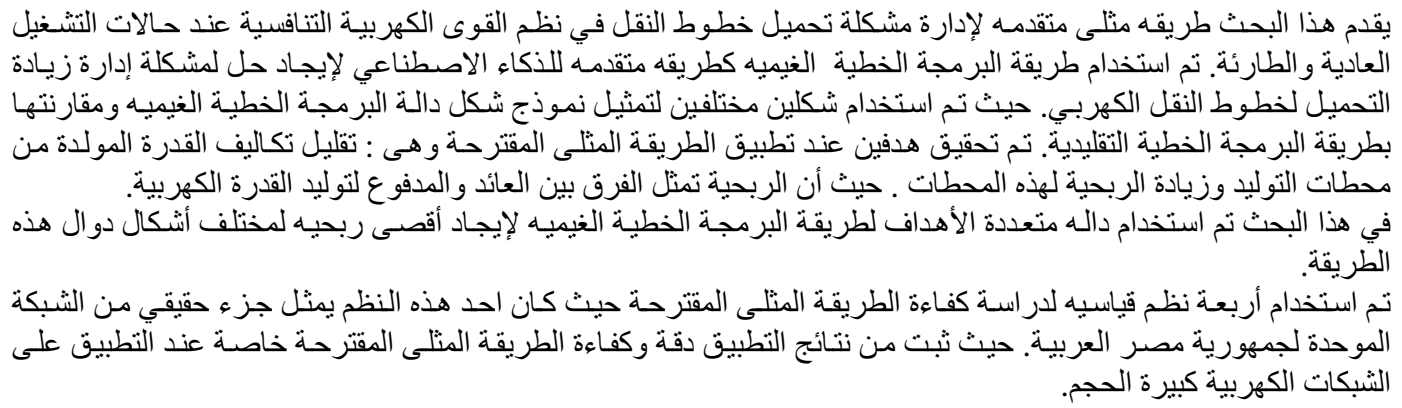

Keywords: congestion, Deregulation, FLP, competitive, optimal dispatch and emergency.

\section{INTRODUCTION}

Congestion in a transmission grid occurs due to an operating condition that causes limit violations on one or more of the "flow gates" in the system [1]. Congestion or overload in one or more transmission lines of the system may occur as a result of unexpected outages of generation, sudden increase of demand, tripping of transmission lines, or failures of other equipments [2]. In deregulated power systems, congestion, which can also occur due to commercial reasons, has become a major concern. Fast, transparent, and effective tools are necessary for congestion management [2]. Many recent publications have proposed techniques for congestion management in the deregulated environment [3-6]. The importance of congestion relief as a transmission service is recognized by both the regulating bodies, especially by federal Energy
Regulatory Commission FERC [7], and by utilities and North American Electricity Reliability Council NERC [8].

In recent years, rapid development of the electricity markets has been witnessed through radical changes due to deregulation process. The deregulation process decomposes the traditional vertical integrated system into individual companies to provide a suitable reduction level of consumer prices by means of competition. The competition in electricity market is constrained by the available transfer capabilities and the level of transmission congestion in a market.

Electric power systems around the world, have been forced to operate to almost their full capacities due to the economic constraints. The amount of electric power that can be transmitted between two locations through a transmission network is limited by security and stability constraints. Power flow in 
the lines and transformers should not be allowed to increase to a level where a random event could cause cascaded outages. When such a limit reaches, the system is said to be congested. Managing congestion to minimize the restrictions of the transmission networks in the competitive market has become the central activity of systems operators. It has been observed that the unsatisfactory management of transactions could increase the congestion cost which is an unwanted burden on customers.

Transmission congestion must be eliminated using corrective actions such as phase shifters/FACTS operations and redispatch of generation. In this paper the corrective actions have been used in congestion relief for generation power redispatch using fuzzy linear programming compared with other algorithms.

In this paper, a proposed sensitivity factors are presented to compute the power flows and transmission losses using different FLP membership models dependant on the collected experiences. Furthermore, a maximum profit is obtained using the proposed different FLP models compared with the LP technique as a conventional technique.

\section{MARKET DISPATCH MODEL}

An optimal power flow is formulated for congestion management combining the following two objectives:

Minimizing the cost of generation.

Maximizing the profit. [9]:

The market dispatch formulation may be stated as

$$
\operatorname{Max} P R=\sum_{j=1}^{N D} B_{j}\left(P D_{j}\right)-\sum_{i=1}^{N G} C_{j}\left(P G_{i}\right)
$$

Where;

$\mathrm{Ci}$ (PGi) is the generation unit payment function.

$\mathrm{Bj}(\mathrm{PDj})$ is the Benefit function of power demands.

PGi and PDj are the power generating and power demand for unit $i$, and a certain load bus $j$ respectively.

NG and ND are the number of generating buses and number load of demand buses respectively.

PR presents the profit of power market which is the difference between the market revenue and market payment, (production cost of power generation units).

The market revenue is based on the forecasted market clearing price of electricity. Equation (1) is subjected to the set of system operating constraints including the system power flow equations and line flow limits. The cost and benefits functions are described by quadratic functions as [9]:

$$
C i\left(P G_{i}\right)=a_{G i} P G_{i}^{2}+b_{G i} P G_{i}+c_{G i}, \quad i \in G
$$

$$
B_{j}\left(P D_{j}\right)=a_{D j} P D_{j}^{2}+b_{D_{j}} P D_{j}+c_{D j}, \quad i \in G
$$

Where,

aGi, bGi, cGi are the payment coefficients,

$\mathrm{aDj}, \mathrm{bDj}, \mathrm{cDj}$ are the benefit coefficients,

$G$ and $D$ are the generators and load demand domains.

\section{Power Balance Constraint}

The total power generated by the generation companies should be equal to the forecasted system demand includes both of the actual system demands and power losses, Plosses.

The independent system operator(ISO) is responsible for supplying the system demand and to allocate the transmission losses for system users. The power balance constraint may be written as.

$$
\begin{aligned}
& \sum_{i=1}^{N G} P G_{i}=\sum_{j=1}^{N D} P D_{j}+P_{\text {losses }} \\
& P_{\text {losses }}=P F_{i-j}+P F_{j-i}
\end{aligned}
$$

Where

PFi-j is the power flow form bus $i$ to bus $j$

$P F j-i$ is the power flow form bus $j$ to bus $i$

\section{Congestion Constraint}

For NL-transmission lines, the power flows in transmission network must be less than the maximum bending limits. The ISO is responsible for supplying the system demands and to alleviate the congestion effects. The power in transmission line $\mathrm{k}$, PFk must be less than its maximum limits as [9]:

$$
|P F k| \leq P F k_{\max }, k=1,2, \cdots \cdots \cdots \cdots, N L
$$

The generalized generation distribution factors (GGDF) are used to compute the power flow in transmission line $\mathrm{k}$ as [9]:

$$
P F_{k}=\sum_{i=1}^{N G}\left(D_{k, i} . P G i\right) \quad k=1,2, \ldots \ldots ., N L
$$

Where $D_{k, i}$ are GGDF for line k and generation i. $\mathrm{NL}$ is the number of load buses

\section{Capacity (Physical) Constraints}

The physical limitations of power generation scheduling must be with in maximum and minimum limits as:

$$
P G i_{\min } \leq P G i \leq P G i_{\max } \quad i=1,2,3, \ldots \ldots, N
$$

Also, the demand power must be with in maximum and minimum limits as:

$$
P D i_{\min } \leq P D i \leq P D i_{\max } \quad i=1,2,3, \ldots \ldots, N
$$


Adel A. Abou El-Ela, Ahmed Shobir, Ahmed Shobir and S.Dawoud, "Transmission Congestion Management ..."

\section{PROPOSED FLP MEMBERSHIP MODELS}

The changes in membership models have an effect in the optimization problem. The shape of the membership function is constructed according to the nature of variable variations.

\subsection{Modeling of Objective Function}

The objective is to maximize a certain function (Max PR). The proposed shapes of fuzzy modeling are shown in Figs.1 and 2. The membership generation unit payment function, $\mu(\mathrm{Ci})$, can be written in the following form:

$$
\mu(c)=\left\{\begin{array}{l}
1 \quad c \leq c_{o} \\
\left(c_{1}-c\right) /\left(c_{1}-c_{o}\right) \quad c_{o} \leq c \leq c_{1} \\
0 \quad c \geq c_{1}
\end{array}\right.
$$

Where $\mathrm{c}$ is a point between co and $\mathrm{c} 1$

Figure 1 shows the proposed shape of fuzzy models for the power generation cost functions.

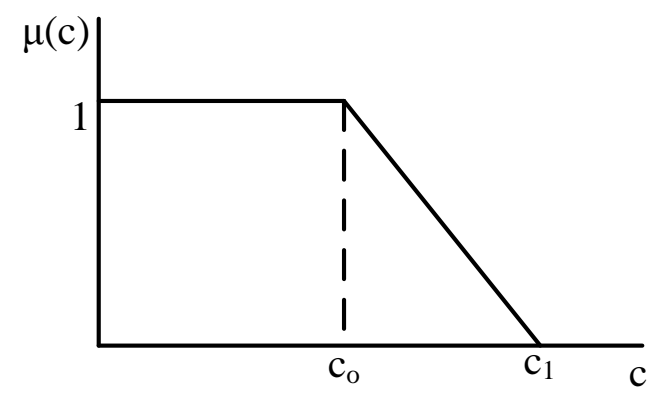

Fig. 1 Semi triangular membership of cost function

The membership benefit function of power demands $(\mathrm{Bj})$ can be written in the following form:

$$
\mu(B)=\left\{\begin{array}{l}
\left(B-B_{O}\right) /\left(B_{1}-B_{O}\right), \quad B_{O} \leq B \leq B_{1} \\
0 \quad \text { otherwise }
\end{array}\right.
$$

Where B is a point between Bo and B1

Figure 2 shows the proposed shape of fuzzy models for the benefits power demand.

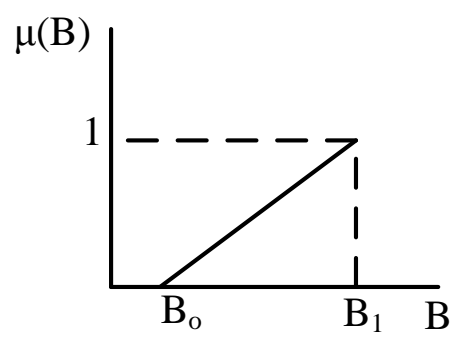

Fig.2 Semi triangular membership of benefit

\subsection{Modeling of Power Generation}

The proposed different shapes of power generation fuzzy membership function can be written in the following form:

$$
\begin{aligned}
& \mu(P G)= \begin{cases}\left(P G-P G_{\text {min }}\right) /\left(P G_{\text {med }}-P G_{\text {min }}\right), & P G_{\text {min }} \leq P G \leq P G_{\text {med }} \\
\left(P G_{\text {max }}-P G\right) /\left(P G_{\text {max }}-P G_{\text {med }}\right), & P G_{\text {med }} \leq P G \leq P G_{\text {max }} \\
0 & P G \geq P G_{\text {max }}\end{cases} \\
& \mu(P G)= \begin{cases}\left(P G-P G_{\min }\right) /\left(P G_{1}-P G_{\text {min }}\right) & P G_{\text {min }} \leq P G \leq P G_{1} \\
1 & P G_{1} \leq P G \leq P G_{2} \\
\left(P G_{\max }-P G\right) /\left(P G_{\max }-P G_{2}\right) & P G_{2} \leq P G \leq P G_{\max } \\
0 & P G \geq P G_{\text {max }}\end{cases}
\end{aligned}
$$

Where PG is a point between min and max values.

However the Power generation can be represented by two fuzzy membership models triangular model (FLP1) and trapezoidal model (FLP2) as shown in Fig.3 and Fig. 4 respectively.

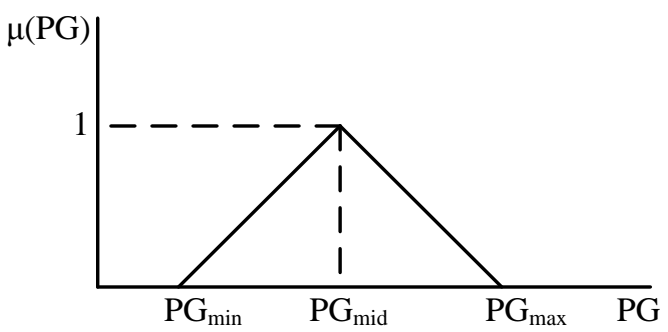

Fig. 3 Triangular membership of generation

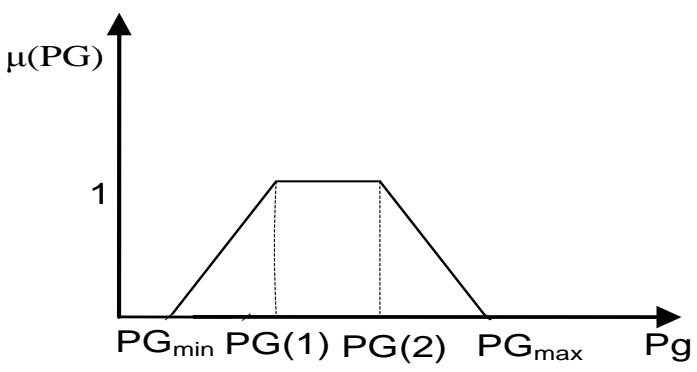

Fig.4 Trapezoidal membership of generation

\subsection{Modeling of Power Demand}

The proposed shape of power demand fuzzy membership function is shown in Fig.5. This function can be written in the following form:

$\mu(P D)=\left\{\begin{array}{l}\left(P D-P D_{\text {min }}\right) /\left(P D_{\text {max }}-P D_{\text {min }}\right), P D_{\text {min }} \leq P D \leq P D_{\text {max }} \\ 0 \quad \text { otherwise }\end{array}\right.$

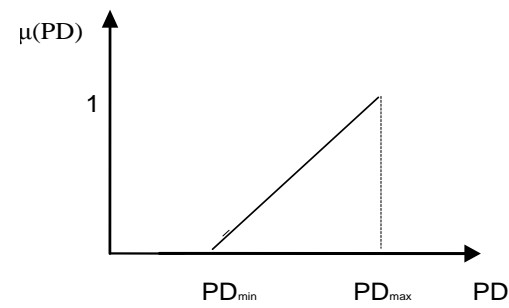

Fig. 5 Semi triangular membership of power demand 
Adel A. Abou El-Ela, Ahmed Shobir, Ahmed Shobir and S.Dawoud, "Transmission Congestion Management ..."

\subsection{Modeling of Power Flow Constraint}

The proposed shape of power flow fuzzy membership function is illustrated by Fig.6. This function can be written in the following form:

$\mu(P F)=\left\{\begin{array}{l}\left(P F-P F_{\text {min }}\right) /\left(P F_{\text {max }}-P F_{\text {min }}\right), \quad P F_{\text {min }} \leq P F \leq P F_{\text {max }} \\ 0 \quad \text { otherwise }\end{array}\right.$

Where, PF is a point between the minimum and maximum power flow limits.

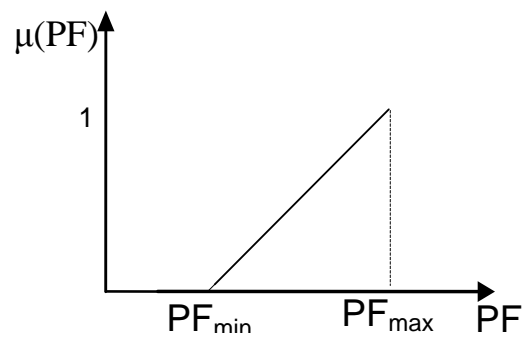

Fig. 6 semi triangular membership of power flow

\section{PROPOSED OPTIMIZATION TECHNIQUE}

Hence, the security constraint optimal power dispatch (SCOD) problem, (Equations (1)-(9)), can be solved using a multi objective optimization problem to find the values of PG, PD and PF and degrees of membership of generated power. The maximization of the degree of membership for objective function $\mu(\mathrm{PR})$, multi-objective optimization problem, can be solved by MAX_MIN $[\mu(\mathrm{PR})]$, which can be written as:

$\operatorname{Max}[\operatorname{Min}(\mu(\mathrm{Ci}), \mu(\mathrm{Bj}), \mu(\mathrm{PG}), \mu(\mathrm{PF})$, $\mu(\mathrm{PD}) \ldots . . . . .)$.

Or $\quad$ Max $\alpha$

Subject to:

$$
\begin{aligned}
& \mu(\mathrm{Ci}) \geq \alpha \\
& \mu(\mathrm{Bj}) \geq \alpha \\
& \mu(\mathrm{pg}) \geq \alpha \\
& \mu(\mathrm{PF}) \geq \alpha
\end{aligned}
$$

Where $\alpha \varepsilon[0,1], \quad \alpha$ is the degree of the problem optimality.

\section{APPLICATIONS \\ 5.1 Test Systems}

Four standard test systems are used to show the capability of the proposed technique for (SCOD) solving using the FLP. The first test system is 5-bus test system which contains 5 buses and 7 transmission lines [10]. The second test system is IEEE 14-bus test system [11], while the third test system is IEEE 30-bus test system [11].Added to that system, a real part of Egyptian United Network. Tables 1 and 2 illustrate the generation and lines data for the 5-bus system. The critical line in 5-bus system is line number 3 . The line number 1 is the critical line in the other systems. The maximum power flow rating of the critical lines are equal to 35, 150, 50 MW for the 3 test systems, respectively.
Table 1, generation bus data for 5-bus test system

\begin{tabular}{|c|c|c|c|c|}
\hline $\begin{array}{c}\text { Bus } \\
\text { No. }\end{array}$ & $\begin{array}{c}\text { PG } \\
\text { min } \\
(\mathrm{MW})\end{array}$ & $\begin{array}{c}\text { PG } \\
\text { max } \\
(\mathrm{MW})\end{array}$ & $\begin{array}{c}\text { PG } \\
\text { initial } \\
(\mathrm{MW})\end{array}$ & $\begin{array}{c}\text { Cost } \\
\text { function } \\
(\$ / \mathrm{hr})\end{array}$ \\
\hline 1 & 10 & 120 & 37.89 & $\begin{array}{c}1.7 \mathrm{P} 1 \\
+.0001 \mathrm{p} 12\end{array}$ \\
\hline 2 & 10 & 90 & 90 & $\begin{array}{c}2.3 \mathrm{P} 2 \\
+.002 \mathrm{P} 22\end{array}$ \\
\hline 5 & 10 & 60 & 60 & $\begin{array}{c}2.2 \mathrm{P} 5+ \\
.0015 \mathrm{P} 52\end{array}$ \\
\hline
\end{tabular}

Table 2, line data for 5-bus test system

\begin{tabular}{|r|c|c|c|r|c|}
\hline $\begin{array}{r}\text { Line } \\
\text { No. }\end{array}$ & $\begin{array}{c}\text { Form } \\
\text { bus }\end{array}$ & $\begin{array}{r}\text { To } \\
\text { bus }\end{array}$ & $\begin{array}{c}\mathrm{R}+\mathrm{jx} \\
\text { (p.u) }\end{array}$ & $\begin{array}{r}\mathrm{y} / 2 \\
(\mathrm{p} . \mathrm{u})\end{array}$ & $\begin{array}{c}\text { PF } \\
\text { initial } \\
\text { (MW) }\end{array}$ \\
\hline 1 & 1 & 2 & $.02+\mathrm{j} .06$ & .06 & -2.082 \\
\hline 2 & 1 & 3 & $.08+\mathrm{j} .24$ & .05 & 21.469 \\
\hline 3 & 2 & 3 & $.06+\mathrm{j} .18$ & .04 & 30.485 \\
\hline 4 & 4 & 2 & $.06+\mathrm{j} .18$ & .04 & $-30.795 *$ \\
\hline 5 & 2 & 5 & $.04+\mathrm{j} .12$ & .03 & 25.221 \\
\hline 6 & 3 & 4 & $.01+\mathrm{j} .03$ & .02 & 4.595 \\
\hline 7 & 4 & 5 & $.08+\mathrm{j} .24$ & .05 & -10.87 \\
\hline
\end{tabular}

* Denotes the overflow in line.

Two different operation conditions are considered for congestion of lines, which are normal and emergency conditions.

The emergency conditions may be occurring in the three test systems which are:

1. Sudden increase in load demand.

2. Unexpected outage of lines.

3. Unexpected outage of units inside the generation plant.

\subsection{Results and comments}

Tables 3-5 show the comparison between the results obtained using different shapes of fuzzy membership models (FLP1 and FLP2) and linear programming techniques (LP). Table 3 shows a comparison between different optimization techniques for 5-Bus System at normal operation

\begin{tabular}{|c|c|c|c|c|}
\hline Variables & $\begin{array}{c}\text { Max } \\
\text { limit }\end{array}$ & LP & FLP1 & FLP2 \\
\hline PG 1(MW) & 120 & 61.88 & 78.58 & 78.1 \\
\hline PG 2(MW) & 90 & 65.93 & 55.01 & 49.86 \\
\hline PG 5(MW) & 60 & 60 & 54.29 & 59.63 \\
\hline PD1(MW) & 18.5 & 18.49 & 18.5 & 18.5 \\
\hline PD 3(MW) & 46.25 & 46.23 & 46.25 & 46.25 \\
\hline PD 4(MW) & 46.25 & 46.23 & 46.25 & 46.25 \\
\hline PD 5(MW) & 74 & 73.97 & 74 & 74 \\
\hline PF1(MW) & 34 & 18.5 & 32.51 & 32.38 \\
\hline PF2(MW) & 32 & 25.34 & 28.39 & 27.98 \\
\hline PF3(MW) & 35 & 28.79 & 28.19 & 27.68 \\
\hline PF4(MW) & 30 & -29.45 & -29.24 & -28.58 \\
\hline PF5(MW) & 45 & 24.58 & 28.36 & 24.25 \\
\hline PF6(MW) & 45 & 6.7 & 9.06 & 8.15 \\
\hline PF7(MW) & 12 & -10.18 & -8.13 & -9.69 \\
\hline \multicolumn{2}{|c|}{ profit(L.E/MW) } & 294.87 & 304.46 & 304.8 \\
\hline \multicolumn{2}{|l|}{$\mathrm{G}(\mathrm{MW})$} & 187.81 & 187.89 & 187.89 \\
\hline \multicolumn{2}{|l|}{$\mathrm{D}(\mathrm{MW})$} & 185 & 185 & 185 \\
\hline
\end{tabular}
conditions with congestion of line 3 .

Table 3, Comparison between LP, FLP1 and FLP2 optimization techniques for 5-bus system 
Adel A. Abou El-Ela, Ahmed Shobir, Ahmed Shobir and S.Dawoud, "Transmission Congestion Management ..."

Table 4, Comparison between different optimization techniques for 14-bus system

\begin{tabular}{|l|l|l|l|l|}
\hline & $\begin{array}{c}\text { Max } \\
\text { limit }\end{array}$ & LP & FLP1 & FLP2 \\
\hline PG 1(MW) & 260 & 195.85 & 203.07 & 216.52 \\
\hline PG 2(MW) & 80 & 80 & 72.95 & 59.51 \\
\hline PD 2(MW) & 21.7 & 21.68 & 21.7 & 21.7 \\
\hline PD 3(MW) & 94.7 & 94.61 & 94.7 & 94.7 \\
\hline PD 4(MW) & 47.8 & 47.76 & 47.8 & 47.8 \\
\hline PD 5(MW) & 7.6 & 7.6 & 7.6 & 7.6 \\
\hline PD 6(MW) & 11.7 & 11.7 & 11.7 & 11.7 \\
\hline PD 9(MW) & 29.5 & 29.5 & 29.5 & 29.5 \\
\hline PD 10(MW) & 9 & 8.99 & 9 & 9 \\
\hline PD 11(MW) & 3.5 & 3.5 & 3.5 & 3.5 \\
\hline PD 12(MW) & 6.1 & 6.09 & 6.1 & 6.1 \\
\hline PD 13(MW) & 13.5 & 13.5 & 13.5 & 13.5 \\
\hline PD 14(MW) & 14.9 & 14.9 & 14.9 & 14.9 \\
\hline PF1(MW) & 150 & 126.23 & 132.31 & 143.66 \\
\hline Profit(L.E/MW) & & 634.61 & 644.07 & 660.81 \\
\hline G(MW) & 275.85 & 276.03 & 276.03 \\
\hline \multicolumn{2}{|l|}{ D (MW) } & 260 & 260 & 260 \\
\hline
\end{tabular}

Where $\mathrm{G}$ is power generation and $\mathrm{D}$ is the power demand.

Table 5, comparison between different optimization techniques for 30-bus system

\begin{tabular}{|l|l|l|l|l|}
\hline & $\begin{array}{l}\text { Max } \\
\text { limit }\end{array}$ & LP & FLP1 & FLP2 \\
\hline PG 1(MW) & 80 & 32.93 & 29.63 & 30.98 \\
\hline PG 2(MW) & 80 & 80 & 79.71 & 79.73 \\
\hline PG 5(MW) & 40 & 40 & 40 & 39.86 \\
\hline PG 8(MW) & 50 & 44.19 & 49.93 & 49.83 \\
\hline PG11(MW) & 30 & 30 & 30 & 29.9 \\
\hline PG13(MW) & 55 & 55 & 54.89 & 54.81 \\
\hline PF1(MW) & 50 & 50 & 48.18 & 49.15 \\
\hline Profit(L.E/MW) & 1304 & 1324 & 1325 \\
\hline G(MW) & & 284.5 & 284 & 285 \\
\hline \multicolumn{2}{|l|}{ D(MW) } & 280 & 280 & 280 \\
\hline
\end{tabular}

Table 6, a comparison between different optimization techniques for 52-bus DELTA region with 8 generation buses and 57 lines with line 5 overflows with max value 50

\begin{tabular}{|c|c|c|c|c|}
\hline & $\begin{array}{c}\text { Max } \\
\text { limit }\end{array}$ & LP & Flp1 & Flp2 \\
\hline PG $_{1}(\mathrm{MW})$ & 250 & 16 & 242.11 & 242 \\
\hline PG $_{2}$ (MW) & 250 & 150.87 & 11.67 & 11.58 \\
\hline PG $_{3}(\mathrm{MW})$ & 250 & 150.87 & 48.93 & 48.83 \\
\hline PG $_{4}(\mathrm{MW})$ & 250 & 44.03 & 242.11 & 242.31 \\
\hline PG $_{5}(\mathrm{MW})$ & 375 & 226.31 & 12.67 & 12.6 \\
\hline PG $_{6}(\mathrm{MW})$ & 250 & 16 & 242.11 & 242.28 \\
\hline PG $_{7}(\mathrm{MW})$ & 250 & 150.87 & 94.57 & 92.67 \\
\hline PG $_{8}$ (MW) & 250 & 150.87 & 11.67 & 11.47 \\
\hline PF $_{5}$ (MW) & 50 & -36.56 & 39.54 & 49.72 \\
\hline \multicolumn{2}{|c|}{ Profit(L.E/MW) } & 779 & 876.27 & 890.6 \\
\hline \multicolumn{2}{|c|}{ G(MW) } & 905 & 905 & 905 \\
\hline \multicolumn{2}{|c|}{ D(MW) } & 889 & 889 & 889 \\
\hline
\end{tabular}

Tables (3-6) show the comparison of profit for two different fuzzy modeling and LP model. It can be noticed that: FLP2,FLP1 more profits are obtained than LP and the profits are increased with increasing of system size while all the overflows are removed.

Table 7 shows the profits which is obtained using all technique for four systems.
Table 7, A comparison between profits (L.E/MW) for the different optimization techniques

\begin{tabular}{|c|c|c|c|}
\hline & Profit LP & Profit FLP1 & Profit FLP2 \\
\hline 5 bus & 304.8 & 304.46 & 294.87 \\
\hline 14 bus & 660.81 & 644.07 & 634.61 \\
\hline 30 bus & 1325 & 1324 & 1304 \\
\hline 52 bus & 890.6 & 876.27 & 779 \\
\hline
\end{tabular}

The solution of FLP2 (trapezoidal shapes of generation) has maximum profit for all test systems.

\subsection{Emergency conditions}

\section{Unexpected outage of transmission line}

Tables 8, 9, 10, show the profit of POT using different optimization techniques (LP, FLP1, FLP2) of line outage compared profit using LP, FLP1andFLP2. FLP2 for four standard systems.

Table 8 A comparison between different optimization techniques for 5-bus system

\begin{tabular}{|c|c|c|c|}
\hline $\begin{array}{c}\text { Line } \\
\text { Outage }\end{array}$ & \multicolumn{3}{|c|}{ Line outage of line 1} \\
\hline Technique & LP & FLP1 & FLP2 \\
\hline PG $_{1}(\mathrm{MW})$ & 34.47 & 34.48 & 34.4 \\
\hline PG $_{2}$ (MW) & 81.54 & 80.87 & 80.6 \\
\hline PG $_{5}(\mathrm{MW})$ & 59.02 & 59.99 & 59.95 \\
\hline PD1(MW) $^{\prime}$ & 17.32 & 22.2 & 22.2 \\
\hline PD3(MW) & 43.29 & 54.99 & 55.5 \\
\hline PD4(MW) & 43.29 & 37.03 & 36.78 \\
\hline PD5(MW) & 69.26 & 59.25 & 58.59 \\
\hline PF1(MW) & 0 & 0 & 0 \\
\hline PF2(MW) & 17.12 & 17.09 & 17.05 \\
\hline PF3(MW) & 29.52 & 29.49 & 29.42 \\
\hline PF4(MW) & -29.45 & -29.42 & -29.32 \\
\hline PF5(MW) & 22.02 & 21.43 & 21.31 \\
\hline PF6(MW) & 2.39 & 2.25 & 2.23 \\
\hline PF7(MW) & -11.45 & -11.71 & -11.71 \\
\hline Profit(L.E/M) & 264.15 & 307.35 & 308.4 \\
\hline G(MW) & 175.04 & 175.35 & 174.95 \\
\hline D(MW) & 173 & 173 & 173 \\
\hline & & & \\
\hline & & & \\
\hline
\end{tabular}

Table 9 A comparisons between different optimization techniques for 14-bus system

\begin{tabular}{|r|r|r|r|r|}
\hline (L.E/MW) & L1 & L3 & L6 & \multicolumn{1}{c|}{ L7 } \\
\hline Profit LP & 1284.77 & 1236.91 & 1283.61 & 1286.58 \\
\hline $\begin{array}{r}\text { Profit } \\
\text { FLP1 }\end{array}$ & 1326.4 & 1378.85 & 1348.84 & 1317.9 \\
\hline $\begin{array}{r}\text { Profit } \\
\text { FLP2 }\end{array}$ & 1328.85 & 1381.11 & 1354.07 & 1335.39 \\
\hline G(MW) & 287 & 275 & 278 & 279 \\
\hline D(MW) & 282 & 269 & 274 & 274 \\
\hline
\end{tabular}


Adel A. Abou El-Ela, Ahmed Shobir, Ahmed Shobir and S.Dawoud, "Transmission Congestion Management ..."

Table 10 A comparison between different optimization techniques for 30-bus system

\begin{tabular}{|c|c|c|c|}
\hline (L.E/MW) & L1 & L2 & L3 \\
\hline Profit LP & 1284.77 & 1287 & 1236.91 \\
\hline Profit FLP1 & 1326.4 & 1345.82 & 1378.85 \\
\hline Profit FLP2 & 1328.85 & 1348.91 & 1381.1 \\
\hline G(MW) & 287 & 282 & 275 \\
\hline D(MW) & 282 & 275 & 269 \\
\hline
\end{tabular}

Form Tables 8-10 maximum profit of POT are obtained using the proposed FLP2.

\section{Sudden increase in load demand}

Tables 11 and 12 show the profit of POT using different optimization techniques (LP, FLP1 and FLP2) for three test systems at different loading conditions.

Table 11 A comparison between different optimization techniques for 14-bus system

\begin{tabular}{|c|c|c|c|}
\hline $\begin{array}{c}\text { Load } \\
\text { increase }\end{array}$ & $5 \%$ & $10 \%$ & $15 \%$ \\
\hline Profit LP(L.E/MW) & 606.91 & 573.58 & 569.98 \\
\hline $\begin{array}{c}\text { Profit } \\
\text { FLP1(L.E/MW) }\end{array}$ & 705.74 & 764.29 & 829.11 \\
\hline $\begin{array}{c}\text { Profit } \\
\text { FLP2(L.E/MW) }\end{array}$ & 706.15 & 767.31 & 829.11 \\
\hline G(MW) & 281 & 286 & 291 \\
\hline D(MW) & 265 & 270 & 274 \\
\hline
\end{tabular}

Table 12 A comparison between different optimization techniques for 30-bus system

\begin{tabular}{|c|c|c|c|}
\hline $\begin{array}{c}\text { Load } \\
\text { increase }\end{array}$ & $5 \%$ & $10 \%$ & $15 \%$ \\
\hline Profit LP(L.E/MW) & 1329.44 & 1329.65 & 1359.15 \\
\hline $\begin{array}{c}\text { Profit } \\
\text { FLP1(L.E/MW) }\end{array}$ & 1410.66 & 1507.49 & 1593.48 \\
\hline $\begin{array}{c}\text { Profit } \\
\text { FLP2(L.E/MW) }\end{array}$ & 1413.28 & 1515.08 & 1594.18 \\
\hline G(MW) & 286 & 286 & 292 \\
\hline D(MW) & 281 & 281 & 287 \\
\hline
\end{tabular}

\section{Unexpected outage of units form the generation} plant

Tables 13 and 14 show the profit of POT using different optimization technique (LP, FLP1, FLP2) for two test systems at different unexpected outage of units form the generation plants.

Table 13 A comparison between different optimization techniques for 14-bus

\begin{tabular}{|c|c|c|c|}
\hline $\begin{array}{c}\text { \%outage of } \\
\text { units }\end{array}$ & $10 \%$ & $20 \%$ & $30 \%$ \\
\hline Profit LP & 586.59 & 596.56 & 453.21 \\
\hline Profit FLP1 & 665.39 & 675.17 & 740.58 \\
\hline Profit FLP 2 & 667.85 & 676.68 & 741.19 \\
\hline G(MW) & 269 & 269 & 237 \\
\hline D(MW) & 253 & 253 & 224 \\
\hline
\end{tabular}

Table 14 A comparison between different optimization techniques for 30-bus

\begin{tabular}{|c|c|c|c|}
\hline $\begin{array}{c}\text { \%outage of } \\
\text { units }\end{array}$ & $10 \%$ & $20 \%$ & $30 \%$ \\
\hline Profit LP & 1228.56 & 1119.98 & 1020.08 \\
\hline Profit FLP1 & 1364.84 & 1416.67 & 1469.81 \\
\hline Profit FLP 2 & 1366.36 & 1419.28 & 1471.53 \\
\hline G(MW) & 264 & 241 & 218 \\
\hline D(MW) & 259 & 237 & 214 \\
\hline
\end{tabular}

\section{CONCLUSIONS}

An efficient and accurate proposed optimization technique has been applied to solve the transmission congestion management problem in competitive market of power systems at normal and emergency conditions. Two shapes models of fuzzy linear programming memberships (FLP1 and FLP2) have been proposed to find the solution of the transmission congestion management problem. The trapezoidal shape of membership function of power generation FLP2 has the most efficient membership to obtain the maximum profit compared with the other techniques. A multi objective fuzzy linear programming technique has been successfully applied to obtain the maximum profit for different scale power systems, while all the overflows in the different transmissions lines has been removed. A real power system which is apart of Egyptian United Network has been to show the capability of the POT. To find out the maximal profit by maximizing the customers benefit and minimizing the payment of power generation.

\section{REFERENCES}

[1] F. L. Alvarado, "Congestion management in an open market," in Tutorial on Future Needs and Trends in Power System Computing, PICA Conference, May 1997.

[2] Shirmohammadi D, Wollenbarg B, Vojdani A, Sandrin P, Pereira M, Rahimi F, et al. Transmission dispatch and congestion management in the emerging energy market structures. IEEE Trans Power Syst 1998; 13(4):1466-74.

[3] Alomoush MI, Shahidehpur SM. Contingencyconstrained congestion management with a minimum number of adjustments in preferred schedules. Int $\mathrm{J}$ Electrical Power Energy Syst 2000;22(4):277-90.

[4] Hyman LS. Transmission congestion, pricing and incentives[in electricity supply]. IEEE Power Eng Rev 1999;198:4-10.

[5] Christie R, Wangensteen I. The energy market in norway and sweden: congestion management. IEEE Power Eng Rev Power Eng Lett 1998;61-2.

[6] Glavitsch H, Alvarado F. Management of multiple congested conditions in unbundled 
Adel A. Abou El-Ela, Ahmed Shobir, Ahmed Shobir and S.Dawoud, "Transmission Congestion Management ..."

operation of a power system. IEEE Trans Power Syst 1998; 13(3):1013-9.

[7] “FERC open access documents,” April 1996.

[8] NERC Interconnected Operations Services Working Group, "Defining interconnected operations services under open access," Final Report, March 1997.

[9]R.A .El-Sehiemy and A A.Abou El-Ela / International Energy Journal 10 (2009)
[10] A.A. Abou El-Ela, M. A. Bishr, S. Allam and R. El-sehiemy, "Optimal preventive Control Actions Using Multi- Objective Fuzzy Linear Programming Technique", printed in Journal of Electric Power System Research, U.S.A, 2005.

[11]Zimmerman,R.D.,Murillo-Sanchez,C.E.,and GanD.2005. MATPOWER Version 3.0 a MATLAB Power System Simulation Package: www.pesercll.edu/matpower/ 